\title{
PREFACE: INNOVATIONS IN LIBRARY PRACTICE AND INFORMATION RESEARCH
}

\section{INTRODUCTION}

This special issue of The International Journal of Innovations in Online Education (IJIOE) on innovations in library practice and information science research assumes readers already are well aware of many of the broad and deep shifts-technological, cultural, and pedagogical-changing the ways in which teaching and learning occur today. Our collective understanding of learning has expanded beyond the traditional classroom and even beyond online classrooms to include a fuller spectrum of formal and informal environments and activities. We recognize that learners include children, adults, and lifelong information seekers who want flexible, customizable, and personalized options to meet their needs best, whenever and wherever those needs occur.

Our primary intent with this issue is to affirm and provide insights into the varied and relevant ways that librarians and information science researchers are on the front lines of learning and providing valuable expertise, support, and resources. We selected nine papers from contributing authors that illustrate innovative research, services, and librarybased activities that advance contemporary teaching and learning in diverse contexts. Most of the research and activities selected for this special issue were chosen primarily from among projects funded in recent years by the Institute of Museum and Library Services (IMLS), which is the primary source of federal government support for libraries, archives, and museums in the United States. The IMLS peer-review process is robust in terms of identifying and supporting activities with potential broad national impact and that can help move the library and archive fields forward. Therefore, in some ways, this issue reflects the expertise of hundreds of peer reviewers who have identified projects that are innovative and far reaching. As readers explore the nine articles in this special issue, they will notice innovation and impact can take many forms, often dependent upon local context and not always technology based.

Our issue is divided into three sections: research, practice, and theory. The research section includes four articles that provide accounts of design-based investigations as well as mixed methods studies involving surveys, interviews, and observations of both teachers and learners. The practice section pays attention to the shaping and refining of contemporary practice in libraries and among librarians and library and information science faculty. These four articles illustrate contemporary efforts around librarians' capacity building and self-efficacy development; continuing education and facilitation strategy adoption; formal education featuring real world digital preservation consultancy projects; 
and a community of practice that has emerged in response to changing technology, which is centered around indigenous world views. The final section includes one article concentrating on learning theory in relation to crowdsourcing and user-generated content in educational contexts. In keeping with IJIOE's focus on science, technology, engineering, arts, and mathematics (STEAM) online education, all of the articles focus on either science, technology, engineering, and mathematics (STEM) in general, such as STEM education, Maker activities, and STEM professional development, or technology in particular, including online content and its modalities, forms, and readability; digital preservation; technology-focused professional development; and dynamic, participatory sites concentrated on user-generated content. Following is a brief summary of the articles in each section.

\section{RESEARCH}

Jill Castek and Gloria E. Jacobs, in Promising Library Practice: Assessing and Instructing Digital Problem Solving, discuss a research-based framework and tools for librarians to assess the digital problem-solving abilities of library users. In particular, the authors focus on how librarians can assist underserved adult learners such as English learners and adults with learning disabilities, who often lack access to hardware and necessary services to participate fully in a digital world. Castek and Jacobs define and compare the ideas of digital literacy and digital problem solving and review pre-existing assessment materials available to libraries, including problem solving in technology rich environments (PSTRE), NorthStar Digital Literacy Assessment, and GCF Learn Free, pointing out that none provides insights necessary for in the moment, library-based facilitation. The authors then discuss the results of research with 450 library users-211 of whom completed a digital problem-solving assessment and 18 of whom were interviewed and observed-and review four main concepts arising from their data analysis. Castek and Jacobs conclude with implications from their research for library practice, including potential trajectories for learners in terms of the kinds of software and platforms that may best serve their developmental needs at different times for a variety of self-directed learning purposes and an overall more structured approach to thinking about assessment of learning in libraries.

Focusing on nontraditional resources in STEM education, Rich Gazan, Katie MacLean, and Natalie Wahl, in Participative Resources, Practices, and Information Literacy Standards in Online STEM Education, investigate how undergraduate STEM students use supplemental learning resources, including social media platforms and dynamic, usergenerated content sites outside of course instruction. The authors define information literacy and then provide an overview of social research practice; pedagogical affordances of digital and social media; participative STEM education; STEM and information literacy; learning communities and the online STEM education environment; and online learning 
communities and information literacy. They then discuss their own iterative participatory design research with instructors, librarians, and students during which they analyzed five information literacy standards and investigated the role of supplemental learning resources, including surveying 112 students in an undergraduate computer science course. Gazan, MacLean, and Wahl find, among other things, that students access, apply, and can discern quality indicators of social and participative resources as a supplement to assigned course learning resources, are more likely to search on their own for supplemental content, and value non-social Web resources most highly, suggesting that librarians more tightly integrate portals, LibGuides, and information literacy instruction into their course syllabi. The authors also discuss related participant observation work where a much higher level of participative resources and practice was integrated into the sessions than previously documented.

Amelia Gibson and Dana Hanson-Baldauf, in "I Want It the Way I Need It": Modality, Readability, and Format Control for Autistic Information Seekers Online, share information about a qualitative analysis of 16 in-depth interviews with autistic individuals and parents that explores themes related to information poverty and the influence of control and power in online environments toward growth, self-determination, and personal agency. The authors discuss the perspectives of participants on information seeking, including why some platforms are preferred over others in terms of control of modality, format, and readability of information. The authors found, among other things, that participants preferred video streaming and multimedia content to address their information needs and that social media function as personal infrastructure for supportive place-based communities. They conclude with questions and considerations for researchers, creators of online learning sites, and library and information science faculty who teach in environments that support neuro-divergent learners.

Aubrey Rogowski, Mimi Recker, and Victor R. Lee, in Designing Online Support Guides for Librarians Managing STEM Maker Activities, document a design-based research project that yielded online instructional guides about STEM Maker programming and activities for youth. The authors describe small town and rural school and public librarians' practices and perceptions around Maker activities, including those addressing constraints and affordances, and how the authors engaged in a research process designed to help librarians implement activities through testing, revising, and refinement of materials. The project, addressing a lack of preparation in STEM programming facilitation in the library field, resulted in three kinds of open and free online instructional guides and four design guidelines. 


\section{PRACTICE}

Karen Brown, Karen Gareis, Meighan Maloney, and Daniel Rockmore, in From Science Program Conveners to Science Program Developers: An Online Professional Development Program for Rural Librarians, describe a STEM public programming initiative for adults in rural communities that builds the capacity of public libraries to serve as community hubs for STEM learning. The authors talk about two federally funded programs that help develop rural librarians' self-efficacy as community-embedded informal STEM learning facilitators and program developers, including how the projects define selfefficacy, feature a scaffolded learning approach for the librarians' professional development, and incorporate a digital platform where the librarians and science partners collaborate on the interpretation and use of STEM content. The authors conclude with major takeaways from an evaluation of the materials, including that librarians felt an online discussion community was useful in helping them plan and deliver programs, feel connected to a larger professional community, and be more comfortable answering questions in areas where they lack deep content knowledge.

Keliann LaConte, Brooks Mitchell, Ginger Fitzhugh, and Carrie Liston, in Online Learning through the STAR Library Network: Resources, Networking, and Applied Practice in STEM Program Facilitation, write about online continuing education that helps librarians learn about and adopt STEM facilitation strategies, bridging theory and practice, as part of the Science-Technology, Activities, and Resources (STAR) Library Network, or STAR Net. STAR Net is an interactive learning network for libraries and their communities developed by the Space Science Institute in partnership with the American Library Association and other organizations. The authors present an overview of the landscape of STEM teaching and learning in libraries; librarians' articulated perceptions of barriers to offering STEM programs; and a description of how STAR Net, through development of programs and resources, tries to help librarians overcome those barriers. The authors focus on webinars, in particular, since they serve a key function in helping hundreds of librarians across the United States increase knowledge, confidence, and interest in STEM program facilitation by getting information, interacting with STEM resource providers, and participating in hands-on training offered in conjunction with important STEM events and initiatives.

Trevor Owens, in Cultivating Craft in Context: Graduate Students as Digital Preservation Consultants for Small Cultural Heritage Organizations, describes a digital preservation graduate seminar where students act as digital preservation consultants for staff at small cultural heritage organizations. The students are better prepared for work as digital preservation practitioners through hands-on, documented work addressing real world resource constraints. Unlike traditional internships or practicums, staff members at the organizations are also learners. They are able to advance their own practice while getting 
access to practical suggestions and resources. Owens shares five components of digital preservation consultant projects; student and staff perspectives on the value of the approach of the course; results and impacts for organizations; and how higher education can take this model forward.

Loriene Roy and Mary Anne Hansen, in Project Update: Exploring Ways to Incorporate New Online Learning Technologies into the Tribal College Librarians Institute, provide a project update about the Tribal College Librarians' Institute (TCLI), an international professional development gathering and related community of practice serving the needs of college students and faculty in tribal communities. TCLI began almost 30 years ago when tribal college librarians reached out to the Montana State University (MSU) library to get help integrating computers, email, and other technologies into library services. The authors discuss how and why online innovations can be unattainable at tribal colleges and present an overview of the accomplishments and challenges of TCLI as an online learning community that brings an indigenous world view to higher education. Future goals for TCLI include incorporating more web conferencing and use of social media as well as helping the field respond to changing demographics of emerging library professionals and leaders.

\section{THEORY}

Manasa Rath and Chirag Shaw, in Learning in Crowdsourced Environments: Where Are We Going and How Do We Get There, examine concerns related to crowdsourcing in learning environments, particularly online participatory sites like popular question and answer ( $Q$ \& $A)$ sites where learners can develop and share free and easily accessible content without intervention from or evaluation by intermediary authorities. The authors provide a review of learning theories and crowdsourcing in educational settings; discuss benefits and risks of learning in these environments; and propose tangible and practical solutions to minimizing potential hazards of crowdsourcing in educational contexts, including a Web-based browser plug-in that would automatically evaluate the quality of user-generated content (UGC).

\section{FINAL THOUGHTS}

While some authors explain nuts-and-bolts details of specific programming, networking, and resource development efforts, all together these papers raise questions and challenges about online teaching and learning that reach far beyond libraries. We have no illusions that this issue represents fully the substantial breadth of current innovations in libraries and information science research. Instead, we see this special issue as an opportunity to increase awareness among non-librarian readers and to generate interest and engagement that might lead to additional future issues of IJIOE focused on libraries. 
Guest Editors:

\section{Sandra Annette Toro}

Institute of Museum and Library Services

Washington, DC, USA

\section{Chuck Thomas}

University System of Maryland and Affiliated Institutions Library Consortium

Hyattsville, MD, USA 